\title{
Study on Mass Attenuation Coefficients and Optical Properties for Boro-Tellurite Glass doped with Barium
}

\author{
Heba Ali Saudi*, Ghada Adel \\ Physics Department, Faculty of Science, Al-Azhar University, Cairo, Egypt \\ Email address: \\ heba_saudi@hotmail.com (H. A. Saudi) \\ ${ }^{*}$ Corresponding author \\ To cite this article: \\ Heba Ali Saudi, Ghada Adel. Study on Mass Attenuation Coefficients and Optical Properties for Boro-Tellurite Glass doped with Barium. \\ American Journal of Astronomy and Astrophysics. Vol. 6, No. 1, 2018, pp. 21-25. doi: 10.11648/j.ajaa.20180601.13
}

Received: December 30, 2017; Accepted: January 29, 2018; Published: March 8, 2018

\begin{abstract}
The influence of $\mathrm{BaO}$ content on the optical properties such as energy gap, refractive index, optical basicity, molar and oxide ion polarizability, molar refraction and third order nonlinear susceptibility have been studied theoretically in $[0.7$ $\left.\mathrm{TeO}_{2}(0.3-\mathrm{x}) \mathrm{B}_{2} \mathrm{O}_{3} \times \mathrm{BaO}\right](\mathrm{x}=0,0.1,0.2,0.3 \mathrm{~mole} \%)$ and analyzed the parameters related to these compositions with theoretical predictions. The mass attenuation coefficients of glass system have been calculated at different energies. The theoretical results indicate that a decrease of the mass attenuation coefficient with increasing of gamma-ray energies and that glass in the present study may be developed as radiation shielding material and new nonlinear optical materials.
\end{abstract}

Keywords: Borate Glass, Optical Property, Radiation Shields

\section{Introduction}

Increasing the use of gamma active isotopes in support of the application makes the study of the absorption and interaction of gamma radiation in materials an important research field. The photon attenuation coefficients are basic quantities required in determining the attenuation of X-rays and gamma photons in the matter.

The glasses with higher nonlinear optical properties, especially third-order nonlinear susceptibility, are desirable to develop nonlinear waveguide devices applied to optical signal processing [1]. Glasses with higher refractive indices are expected to have higher third-order nonlinear susceptibility values [1]. It was found that bismuth and tellurite glasses possess high optical nonlinearity and have possible application as nonlinear optical materials [2]. Also, the calculation of the refractive index is very important to determine the suitability of glass material to be optical devices [3]. The understanding of optical basicity would be useful for the design of the novel optical functional materials with higher optical performances [4].

The mass attenuation coefficient $(\mu / \rho)$, which is a measure of the average number of interactions between incident photons and matter, that occur in a given mass-per-unit area thickness of the substance encountered. This coefficient can be usually calculated via XCOM data which is a computer program developed by (Berger and Hubbell, 1987) for different elements, mixtures and compounds between $1 \mathrm{keV}$ to $100 \mathrm{GeV}$.

The aim of the present work is studying the physical properties of $\left[0.7 \mathrm{TeO}_{2}(0.3-\mathrm{x}) \mathrm{B}_{2} \mathrm{O}_{3} \mathrm{x} \mathrm{BaO}\right](\mathrm{x}=0,0.1,0.2$, 0.3 mole \%) and the factors which affect gamma-ray transmission with an XCOM computer program of mixture rules [5].

\section{Theoretical Background}

The density of all the glasses under study can be calculated from the following expression:

$$
\mathrm{d}=\mathrm{X}_{\mathrm{TeO} 2} \mathrm{~d}_{\mathrm{TeO} 2}+\mathrm{X}_{\mathrm{BaO}} \mathrm{d}_{\mathrm{BaO}}+\mathrm{X}_{\mathrm{B} 2 \mathrm{O} 3} \mathrm{~d}_{\mathrm{B} 2 \mathrm{O} 3}
$$

Where $\mathrm{X}$ is the molar fraction and $\mathrm{d}$ is the values of theoretical density respectively [6].

The optical electronegativity can be calculated as follows,

$$
\Delta \chi^{*}=\mathrm{X}_{\mathrm{TeO} 2} \Delta \chi^{*}{ }_{\mathrm{TeO} 2} \mathrm{X}_{\mathrm{BaO}} \Delta \chi^{*}{ }_{\mathrm{BaO}}+\mathrm{X}_{\mathrm{B} 2 \mathrm{O} 3} \Delta \chi^{*}{ }_{\mathrm{B} 2 \mathrm{O} 3}
$$

Where $\Delta \chi^{*}$ is the values of the optical electronegativity of $\mathrm{TeO}_{2}, \mathrm{BaO}$, and $\mathrm{B}_{2} \mathrm{O}_{3}$, respectively [7]. 
The optical energy gap can be calculated by [8]

$$
\mathrm{E}_{\mathrm{opt}}=0.2688 \Delta \chi^{*}
$$

The optical basicity can be calculated [8]

$$
\text { Optical basicity }=-0.5 \Delta \chi^{*+1.7}
$$

The electronic polarizability [8] of oxide ions can be

$$
\text { calculated }=0.9 \Delta \chi^{*+3.59}
$$

The third order nonlinear susceptibility in esu units is given by the following relation $[6,9]$,

$$
\chi^{(3)}=\left(1.4 \times 10^{-11}\right) /\left(\left(\mathrm{E}_{\mathrm{opt}}-1.96\right)\left(\mathrm{E}_{\mathrm{opt}}-1.31\right)\left(\mathrm{E}_{\mathrm{opt}}-0.65\right)\right)
$$

The nonlinear refractive index $\mathrm{n}_{2}$ can be expressed as [9],

$$
\mathrm{n}_{2}=\left((12 \times 3.14) / \mathrm{n}_{0}\right)\left(\chi^{(3)}\right)
$$

As a photon makes its path through a matter, there is a probability that it makes an interaction with the material such as absorption (photoelectric effect), scattering (Rayleigh or Compton scattering) or splitting (pair production). Therefore, part of the incident beam of intensity $\left(I_{o}\right)$ will be partially or completely removed from the beam as a result of interaction within the absorber of thickness $t$.

This reduces the transmitted intensity that reaches the to $(I)$, where, introducing $\mu$, the linear attenuation coefficient, $\mu_{\mathrm{m}}$ is a mass attenuation coefficient measure of how strongly a chemical species or substance absorbs or scattering radiation at a given wavelength, per unit mass is given by [5];

$$
\mathrm{I}_{(\mathrm{t})}=\mathrm{I}_{0} \mathrm{e}_{\mathrm{m}}^{-\left(\mu_{\mathrm{m}}\right) \rho \mathrm{t}}
$$

Where $\rho$ is the density, $\mu_{\mathrm{m}}$ is the mass attenuation coefficient $\left(\mathrm{cm}^{2} \mathrm{~g}^{-1}\right)$.

Mean free path (MFP) is the average distance a photon travels between collisions with atoms of the glass sample. It depends on the material and the energy of the photons:

$$
\operatorname{MFP}(\lambda)=1 / \mu
$$

\section{Discussion and Results}

\subsection{Density and Molar Volume}

The values of density for all the studied glasses are listed in table 1. It is clear that, the values of density increase by increasing $\mathrm{BaO}$ content. This increase is due to replacement of a low density of $\mathrm{B}_{2} \mathrm{O}_{3}\left(2.46 \mathrm{~g} / \mathrm{cm}^{3}\right)$ by $\mathrm{BaO}\left(5.72 \mathrm{~g} / \mathrm{cm}^{3}\right)$. Also, it was found that the values of theoretical density are greater than the experimental one [6] due to chemical and topological defects of the prepared samples, It happens in the glass and the guide is to be glass. On the other hand, the molar volume $\left(V_{\mathrm{m}}\right)$ decreases with $\mathrm{BaO}$ content. The decrease in $\mathrm{V}_{\mathrm{m}}$ reveals that the structural changes, due to the increase in $\mathrm{BaO}$ content, have the greater effect than that due to the molecular mass difference.

Table 1. The molar volume, the theoretical and experimental density of the glass samples.

\begin{tabular}{llll}
\hline $\mathbf{x}$ & Density $\left(\mathbf{g} / \mathbf{c m}^{\mathbf{3}}\right)($ Theoretical) & Density $\left(\mathbf{g} / \mathbf{c m}^{\mathbf{3}}\right)(\mathbf{E x p e r i m e n t a l )}$ & $\mathbf{M o l a r}_{\mathbf{v o l u m e}}\left(\mathbf{V}_{\mathbf{m}}\right)\left(\mathbf{g} / \mathbf{c m}^{\mathbf{3}}\right)$ \\
\hline 0 & 4.71 & 4.69 & 28.15 \\
0.1 & 4.81 & 3.38 & 28.00 \\
0.2 & 4.91 & 3.56 & 27.85 \\
0.3 & 5.01 & 3.63 & 27.71 \\
\hline
\end{tabular}

\subsection{The Optical Basicity and Polarizability}

The optical basicity, addresses the ability of oxide glass in contributing the negative charges in the glass matrix. In other words, it defines the electron donating power of the oxygen in the oxide glass. The theoretical optical basicity can be calculated according to the approach proposed by Duffy and Ingram [7]. The values of theoretical optical basicity for all the studied samples are listed in table [2]. The increase in values of optical basicity may be attributed to replacement of a low optical basicity oxide $\mathrm{B}_{2} \mathrm{O}_{3}(0.42)$ by a high- optical basicity oxide $\mathrm{BaO}(1.23)$ and this increase indicates that the glass system is basic in nature.

The relationship between electronic polarizability of oxide ions and optical basicity of oxide $\mathrm{A}_{\mathrm{th}}$ is given by this equation [4], the Electronic polarizability of oxide ion increase with increasing the optical basicity as shown in Table 2.

\subsection{The Molar Refraction and the Average Single Bond Strength}

The values of cation polarizability and the values of oxide ion can be taken from [10]. It is clear that from the values of

\begin{tabular}{|c|c|c|c|c|c|c|}
\hline $\mathbf{x}$ & $\begin{array}{l}\text { Optical } \\
\text { basicity }\left(\mathbf{A}_{\text {th }}\right)\end{array}$ & $\begin{array}{l}\text { Oxide ion polarizability } \\
\left(\alpha^{02-}\right)\left(A^{0}\right)^{3}\end{array}$ & $\begin{array}{l}\text { Molar polarizability } \\
\alpha_{\mathrm{m}}\left(\mathrm{A}^{0}\right)^{3}\end{array}$ & $\begin{array}{l}\text { Molar refractivity } \\
\mathrm{R}_{\mathrm{m}}\left(\mathrm{cm}^{3} / \mathrm{mol}\right)\end{array}$ & $\begin{array}{l}\text { Average single bond } \\
\text { strength }(\mathrm{KJ} / \mathrm{mol})\end{array}$ & $\begin{array}{l}\text { Molar polarizability } \\
\alpha_{\mathrm{m}}\left(\mathrm{A}^{0}\right)^{3}\end{array}$ \\
\hline 0 & 0.798 & 1.915 & 5.523 & 13.92 & 311.1 & 5.523 \\
\hline 0.1 & 0.841 & 2.014 & 5.536 & 13.95 & 288.4 & 5.536 \\
\hline 0.2 & 0.884 & 2.125 & 2.548 & 13.98 & 265.7 & 2.548 \\
\hline 0.3 & 0.928 & 2.251 & 5.560 & 14.01 & 242.9 & 5.560 \\
\hline
\end{tabular}
molar polarizability and

The molar refraction $\mathrm{R}_{\mathrm{m}}$ is shown in table2, the glasses under investigation become more polarized by increasing $\mathrm{BaO}$ content and decreasing the values of average single bond strength.

Table 2. Optical basicity, oxide ion polarizability, molar refractivity and average single bond strength of all glass samples. 


\subsection{The Theoretical Optical Energy and Refractive Index}

From Table 3, the decreasing value of theoretical optical band gap energy by increasing $\mathrm{BaO}$ content means that the weaker bond strength of $\mathrm{Ba}-\mathrm{O}(84 \mathrm{KJ} / \mathrm{mol})$ compared to $\mathrm{B}$ $\mathrm{O}(373 \mathrm{KJ} / \mathrm{mol}$ are responsible for the decrease of optical band gap energy[3]. Also, we noticed that the theoretical values of $\mathrm{E}_{\mathrm{opt}}$ are larger than the experimental values [6], this due to the amorphous nature of prepared glass samples.

The refractive index depends on the polarizability of glass material [3]. The values of the refractive index increase by increasing $\mathrm{BaO}$ content as well as the values of molar polarizability increase.

The third-order nonlinear susceptibility in esu units is given by the following relation [6], the values of third order nonlinear susceptibility for all the studied glass samples, were found to be in the range $(2.987-3.561) \times 10^{-13}$ esu as shown in table 3 and figure 1, this means that all the studied samples are probably good candidates for nonlinear optical applications [9, 11 and 12].

Table 3. The optical energy, refractive index and third order nonlinear susceptibility of all glass samples.

\begin{tabular}{lllll}
\hline $\mathbf{x}$ & $\begin{array}{l}\text { Theoretical optical energy } \\
\text { gap }(\mathbf{e V})\end{array}$ & $\begin{array}{l}\text { Experimental optical energy } \\
\text { gap(eV) }\end{array}$ & Refractive index & $\begin{array}{l}\text { Third order nonlinear susceptibility } \chi^{\mathbf{3}} \mathbf{x} 10^{-} \\
\mathbf{1}^{\mathbf{3}} \text { esu. }\end{array}$ \\
\hline 0 & 5.11 & 3.22 & 1.984 & 2.987 \\
0.1 & 5.04 & 2.44 & 1.995 & 3.169 \\
0.2 & 4.96 & 2.29 & 2.006 & 3.360 \\
0.3 & 4.89 & 2.25 & 2.017 & 3.561 \\
\hline
\end{tabular}

In figure 1 and 2 the third-order nonlinear susceptibility as a function of the optical energy gap and refractive index. It is seen that third-order nonlinear susceptibility increases with decreasing the optical energy gap and increasing the refractive index for all the glass samples these means that the nonlinear properties of glass system.

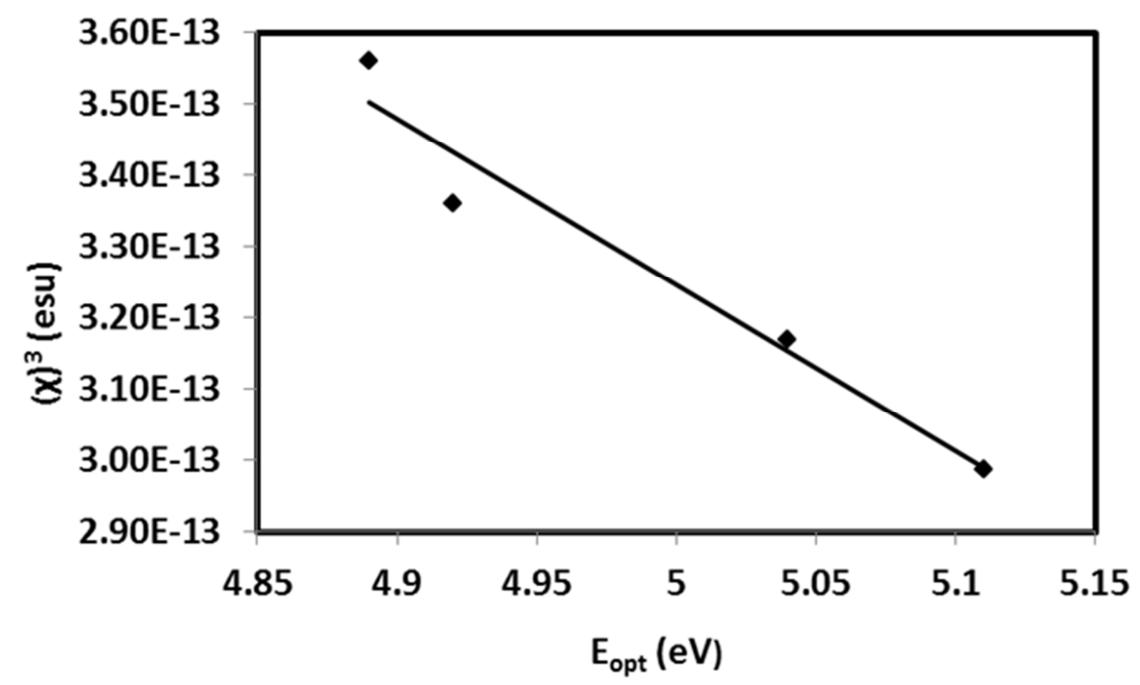

Figure 1. Variation of the third order nonlinear susceptibility as a function of the optical energy gap.

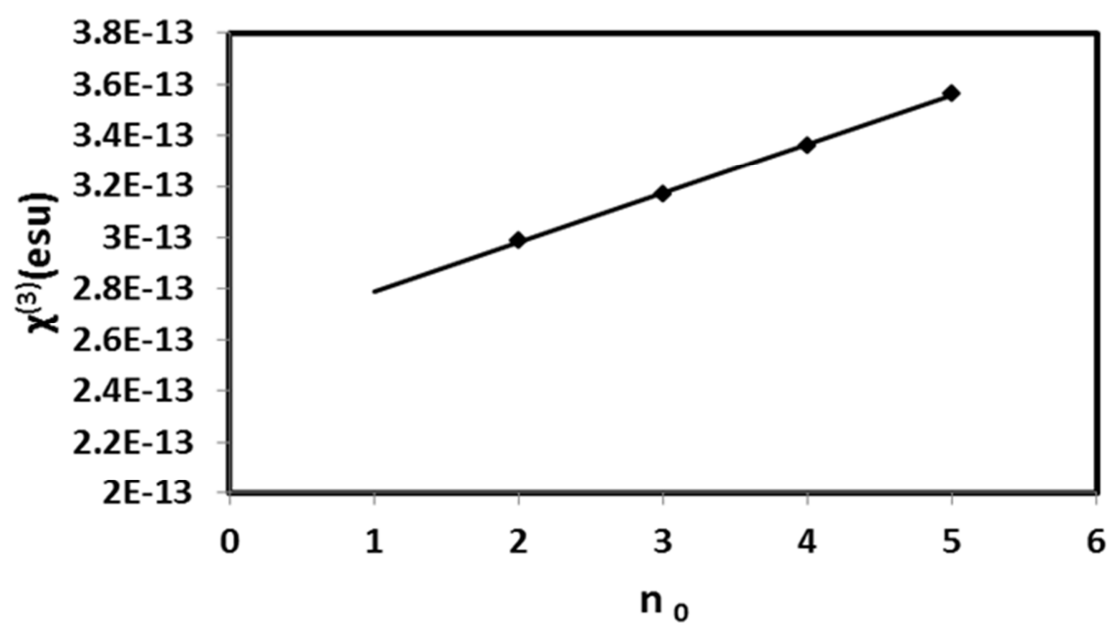

Figure 2. Third order nonlinear susceptibility as a function of the linear refractive index. 


\subsection{Total Mass Attenuation Coefficient $\left(\mu_{m}\right)$ and Shielding Properties}

The theoretical values of mass attenuation coefficients at different energies ranged from (1 keV-100 GeV) low, medium and high energies are shown in Figure 3, where figure 3 shows that the mass attenuation coefficients increase linearly with the weight fraction of $\mathrm{BaO}$ and decrease by increasing gamma-ray energy. This is due to high density and high atomic number of $\mathrm{BaO}$ than $\mathrm{B}_{2} \mathrm{O}_{3}$.

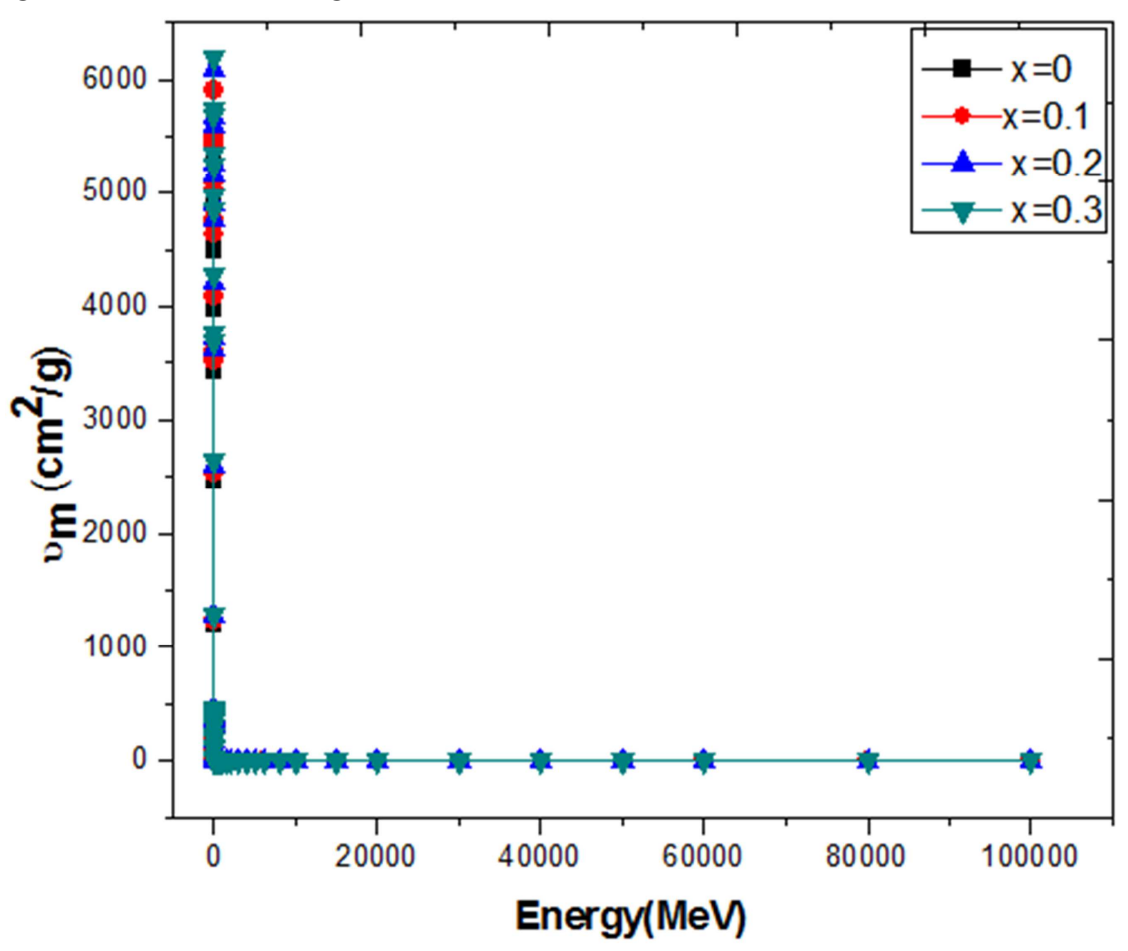

Figure 3. The mass attenuation coefficients as a function of different energies (1keV-100 GeV).

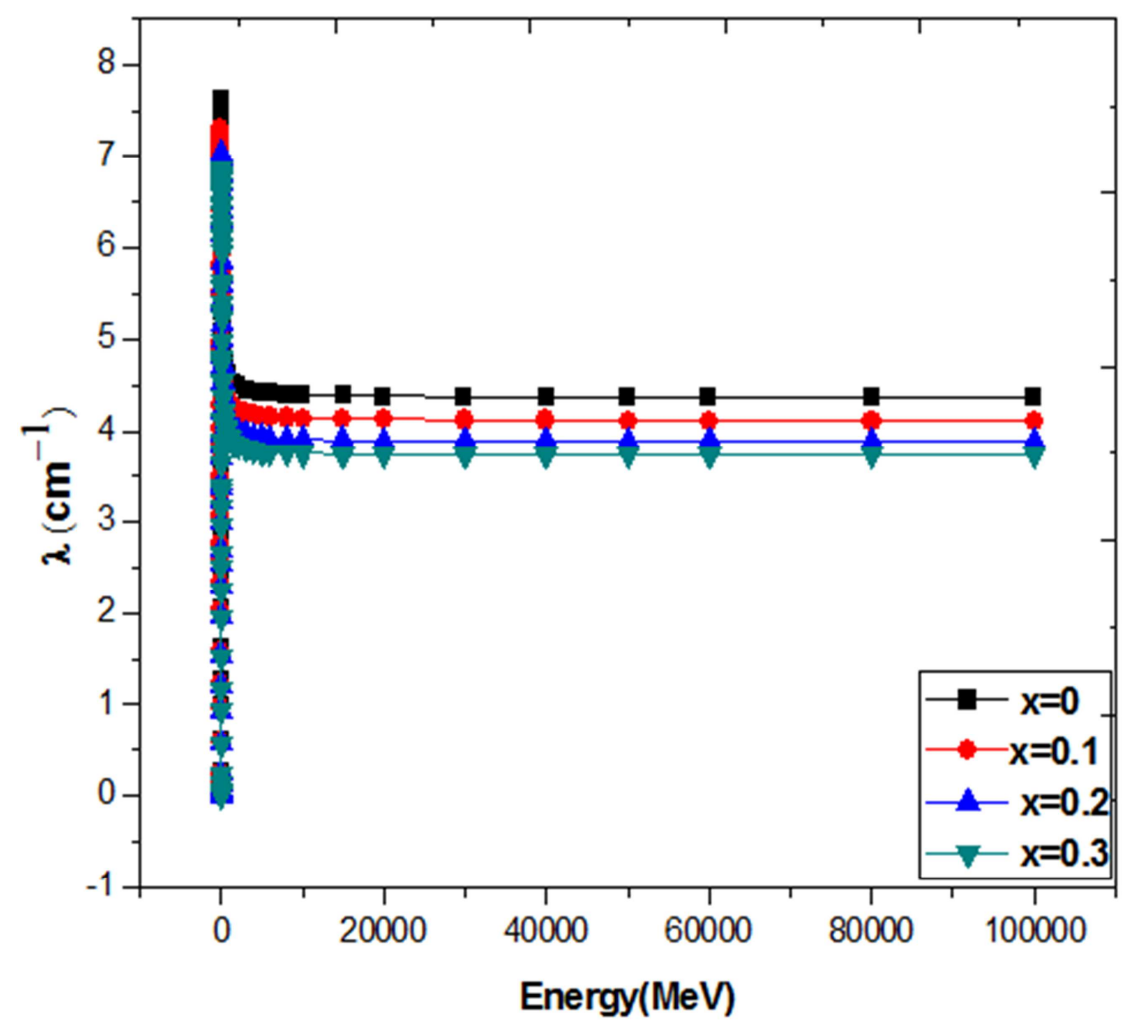

Figure 4. The MFP as a function of different energies (1 keV-100 GeV). 
In figure 4 shows the mean free path $[\operatorname{MFP}(\lambda)]$ as a function of $\mathrm{BaO}$ content, at different $\gamma$ ray energies, for the boro-tellurite glasses. As expected, the MFP decreases with increasing $\mathrm{BaO}$ content and nearly constant at $\mathrm{h}$ energy, which is the most absorbing one of the three compounds. This may be due to the increase in densities of glass samples and the higher values of mass attenuation coefficients.

\section{Conclusion}

1. In the present work, Boro-Tellurite Glass doped with Barium has been observed to be promising gamma ray shielding material capable to minimize the nuclear radiation hazards below the permissible dose. The high value of mass attenuation coefficients and mean free path (MFP) indicates that the volume required for shield design for being less than the traditional shield.

2. The values of electronic polarizability and oxide ion polarizability increase with increasing refractive index and decreasing optical band gap energy. The optical basicity of the glass materials increases by increasing number of oxide ion polarizability and shows that the glass materials are more basic.

3. Finally, all the above values are a good basis for predicting new nonlinear optical shielding materials for gamma-ray.

\section{References}

[1] G. S. Murugan, Y. Ohishi, $\mathrm{TeO}_{2}-\mathrm{BaO}-\mathrm{SrO}-\mathrm{Nb}_{2} \mathrm{O}_{5}$ glasses:a new glass system for waveguide devices applications, $\mathrm{j}$ of Non Cryst. Solids, 341 (2004)86.

[2] T. R. Tasheva and V. V. Dimitrov, Synthesis, structure and nonlinear optical properties of tellurium oxide - bismuth oxide - boron oxide glasses, Bulgarian Chemical Communications, 49(2017)43.

[3] M. N. Azlan, M. K. Hlimah, S. Z. Shafinas and W. M. Daud, "Polarizability and optical basicity of $\mathrm{Er}^{3+}$ ions doped tellurite based glasses", Chalcogenide letters, 11 (2014) 319.

[4] S. P. Singh and B. Karmakar, Bismuth oxide and bismuth oxide doped glasses for optical and photonic applications, Material Sci. and Technologies, chapter 9, (2012), page 229.

[5] H. A. Saudi, Applied Mathematics and Physics, 2013, Vol. 1, No. 4, 143-146.

[6] A. Azuraidaa, M. K. Halimah, A. A. SideKa, C. A. C. Azurahanima, S. M. Iskandarc, M. Ishakd, A. Nurazlinb, Comparative studiesof bismuth and barium boro tellurite glass system: structure and optical properties, Chalcogenide Letters, 12 (2015)497.

[7] J. M. Wu, H. L. Huang, Microwave properties of zinc barium and lead borosilicate glasses, J of Non Crystalline Solids, 260 (1999)116.

[8] C. Jijian, C. Wei, Formation and structure of titanate glasses J of Non Crystalline Solids, 80 (1986)135.

[9] K. Terashima, T. Uchino, T. Hashimota, T. Yoko, Structure and nonlinear optical properties of $\mathrm{BaO} \quad \mathrm{TiO}_{2} \quad \mathrm{~B}_{2} \mathrm{O}_{3}$ GLASSES, J of the ceramic society, 105 (1997)288.

[10] T. Tashera and V. Dimitrov, "Optical properties and structure of $\mathrm{B}_{2} \mathrm{O}_{3} \mathrm{BaOV}_{2} \mathrm{O}_{5}$ Glasses,", J. of Chemical Technology and Metallurgy, 50 (2015) 441.

[11] A, Kumar, D. Mohan, A. Ghosh, A. Gupta, Nonlinear Optical Characterization of Borotellurite Glass of Composition 0.1BaO$0.4 \mathrm{TeO}_{2}-0.5 \mathrm{~B}_{2} \mathrm{O}_{3}$ by Z-Scan Method, Advanced in optical science and engineering, 166 (2015)571.

[12] Heba Saudi, Ghada Adel, Optics, 2017; 6(2): 17-20, $\mathrm{http}: / / \mathrm{www}$.sciencepublishinggroup.com/j/optics, doi: 10.11648/j.optics.20170602.1. 